University of Wollongong

Research Online

Australian Institute for Innovative Materials -

Papers

Australian Institute for Innovative Materials

$1-1-2017$

\title{
Carbon-Encapsulated Sn@N-Doped Carbon Nanotubes as Anode Materials for Application in SIBs
}

\author{
Boyang Ruan \\ University of Wollongong, br970@uowmail.edu.au \\ Haipeng Guo \\ University of Wollongong, hg476@uowmail.edu.au \\ Yuyang Hou \\ University of Wollongong, yh879@uowmail.edu.au \\ Qiannan Liu \\ University of Wollongong, q1953@uowmail.edu.au \\ Yuan-Fu Deng \\ South China University of Technology
}

See next page for additional authors

Follow this and additional works at: https://ro.uow.edu.au/aiimpapers

Part of the Engineering Commons, and the Physical Sciences and Mathematics Commons

Research Online is the open access institutional repository for the University of Wollongong. For further information contact the UOW Library: research-pubs@uow.edu.au 


\title{
Carbon-Encapsulated Sn@N-Doped Carbon Nanotubes as Anode Materials for Application in SIBs
}

\author{
Abstract \\ Carbon-encapsulated Sn@N-doped carbon tubes with submicron diameters were obtained via the simple \\ reduction of C@SnO $2 @ N$-doped carbon composites that were fabricated by a hydrothermal approach. \\ $\mathrm{Sn}$ nanoparticles encapsulated in carbon layers were distributed uniformly on the surfaces of the N-doped \\ carbon nanotubes. The electrochemical performances of the composites were systematically \\ investigated as anode materials in sodium-ion batteries (SIBs). The composite electrode could attain a \\ good reversible capacity of $398.4 \mathrm{mAh} \mathrm{g}-1$ when discharging at $100 \mathrm{~mA} \mathrm{~g} \mathrm{-1,} \mathrm{with} \mathrm{capacity} \mathrm{retention} \mathrm{of}$ \\ $67.3 \%$ and very high Coulombic efficiency of $99.7 \%$ over 150 cycles. This good cycling performance, when \\ compared to only $17.5 \mathrm{mAh} \mathrm{g}-1$ delivered by bare Sn particles prepared via the same method without the \\ presence of $\mathrm{N}$-doped carbon, could be mainly ascribed to the uniform distribution of the precursor SnO 2 \\ on the substrate of $\mathrm{N}$-doped carbon tubes with three-dimensional structure, which provides more reaction \\ sites to reduce the diffusion distance of $\mathrm{Na}+$, further facilitating $\mathrm{Na}+$-ion diffusion and relieves the huge \\ volume expansion during charging/discharging. These outcomes imply that such a $\mathrm{Sn} / \mathrm{C}$ composite \\ would provide more options as an anode candidate for SIBs.

\section{Disciplines} \\ Engineering | Physical Sciences and Mathematics

\section{Publication Details} \\ Ruan, B., Guo, H., Hou, Y., Liu, Q., Deng, Y., Chen, G., Chou, S., Liu, H. \& Wang, J. (2017). Carbon- \\ Encapsulated Sn@N-Doped Carbon Nanotubes as Anode Materials for Application in SIBs. ACS Applied \\ Materials and Interfaces, 9 (43), 37682-37693.

\section{Authors} \\ Boyang Ruan, Haipeng Guo, Yuyang Hou, Qiannan Liu, Yuan-Fu Deng, Guohua Chen, Shulei Chou, Hua-Kun \\ Liu, and Jiazhao Wang
}




\section{Carbon Encapsulated Sn@N-doped Carbon}

\section{Nanotubes as Anode Materials for Application in}

\section{SIBs}

Boyang Ruan ${ }^{a}$, Hai-peng Guo ${ }^{a}$, Yuyang Hou ${ }^{b}$, Qiannan Liu ${ }^{a}$, Yuanfu Deng ${ }^{c}$, Guohua Chen ${ }^{d}$, Shulei Chou ${ }^{a}$, Hua-kun Liu ${ }^{a}$, Jia-zhao Wang ${ }^{a^{*}}$

a: Institute for Superconducting and Electronic Materials (ISEM), University of Wollongong

Wollongong, New South Wales 2522, Australia

b: Intelligent Polymer Research Institute (IPRI), University of Wollongong, Wollongong, New South Wales 2522, Australia

c: School of Chemistry and Chemical Engineering, South China University of Technology,

Guangzhou, 510640 China

d. Department of Mechanical Engineering, The Hong Kong Polytechnic University

Hung Hom, Kowloon, Hong Kong 
KEYWORDS: Hydrothermal approach, N-doped carbon nanotubes, Carbon encapsulated Tin composite, 3-D nanotube, Sodium-ion batteries.

\begin{abstract}
Carbon encapsulated Sn@N-doped carbon tubes with submicron diameters were obtained via the simple reduction of $\mathrm{C} @ \mathrm{SnO}_{2} @ \mathrm{~N}$-doped carbon composites that were fabricated by a hydrothermal approach. Sn nanoparticles encapsulated in carbon layers were distributed uniformly on the surfaces of the N-doped carbon nanotubes. The electrochemical performances of the composites were systematically investigated as anode materials in sodium-ion batteries (SIBs). The composite electrode could attain a good reversible capacity of $398.4 \mathrm{mAh} \mathrm{g}^{-1}$ when discharging at $100 \mathrm{~mA} \mathrm{~g}^{-1}$, with capacity retention of $67.3 \%$ and very high coulombic efficiency of $99.7 \%$ over 150 cycles. This good cycling performance, when compared to only $17.5 \mathrm{mAh} \mathrm{g}^{-1}$ delivered by bare Sn particles prepared via the same method without the presence of N-doped carbon could be mainly ascribed to the uniform distribution of the precursor $\mathrm{SnO}_{2}$ on the substrate of $\mathrm{N}$-doped carbon tubes with three-dimensional structure, which provides more reaction sites to reduce the diffusion distance of $\mathrm{Na}^{+}$, further facilitating $\mathrm{Na}^{+}$ion diffusion, and relieves the huge volume expansion during charging/discharging. These outcomes imply that such a $\mathrm{Sn} / \mathrm{C}$ composite would provide more options as an anode candidate for SIBs.
\end{abstract}

\title{
INTRODUCTION
}

Currently, rechargeable batteries are being widely used in energy storage systems. Since the first commercialization of rechargeable lithium-ion batteries (LIBs) after their invention by Sony 
in 1991, LIBs have been developed as the main power sources for portable electronic devices and are playing more and more important roles in the emerging market for electric vehicles and energy storage for green electrical grids. ${ }^{1-4}$ Nevertheless, the high geographic concentration and limited reserves of lithium in nature will severely restrict the prospects for LIBs in grid energy storage applications and make it a tremendous challenge to meet the demand for lithium resources. ${ }^{5-7}$ Sodium-ion batteries (SIBs) have recently been considered as an alternative to LIBs in energy conversion of intermittent energy sources due to their potentially low cost and the wide distribution of sodium resources. ${ }^{8-11}$ It still remains a big challenge, however, to explore suitable electrode materials, especially anode materials for SIBs, due to the larger ionic radius of $\mathrm{Na}^{+}$ compared with $\mathrm{Li}^{+}$, leading to great volume expansion during charging/discharging. Many materials have been explored to solve this problem, including hard carbon, ${ }^{12,13}$ metal oxides and sulphides,${ }^{14-17}$ intermetallic materials, ${ }^{18,19}$ phosphorus and phosphides, ${ }^{20-23}$ etc. In particular, metallic Sn, with the theoretical capacity of $847 \mathrm{~mA} \mathrm{~h} \mathrm{~g}^{-1}$ based on the alloying/dealloying mechanism $\left(\mathrm{Na}_{15} \mathrm{Sn}_{4}\right)^{24-27}$ has been considered to be a prospective anode material for SIBs. Pure Sn can only achieve very poor cycling performance, however, with dramatic capacity decline over only a few cycles owing to the issue of pulverization. ${ }^{24}$ It would thus be a good idea to encapsulate $\mathrm{Sn}$ in a confined volume with enough space for volume expansion during $\mathrm{Na}$ insertion to avoid pulverization. Generally, it is more convenient to prepare $\mathrm{SnO}_{2}$ nanoparticles than to obtain metallic Sn nanoparticles directly. Additionally, $\mathrm{SnO}_{2}$ can be reduced to metallic Sn by hydrogen reduction at high temperature under an inert atmosphere, and it has unique structures. Many strategies have been employed to alleviate the volume expansion, ${ }^{28,29}$ such as depositing Sn film on hierarchical wood fibers, which displayed stable cycling performance for 400 cycles with an initial capacity of $339 \mathrm{mAh} \mathrm{g}^{-1},{ }^{30}$ using carbonized filter paper decorated with 
Sn@C nanospheres, which showed a high and stable capacity of $550 \mu \mathrm{Ah} \mathrm{cm}^{-2}$ over 100 cycles at $50 \mathrm{~mA} \mathrm{~cm}{ }^{-2},{ }^{31}$ and using ultra-small $\mathrm{Sn}$ nanoparticles embedded in carbon, which achieved a high-rate capacity of $349 \mathrm{mAh} \mathrm{g}^{-1}$, even at $4000 \mathrm{~mA} \mathrm{~g}^{-1}$, and a stable capacity of $\cong 415 \mathrm{mAh}$ $\mathrm{g}^{-1}$ after 500 cycles at $1000 \mathrm{~mA} \mathrm{~g}^{-1} .^{32}$

$\mathrm{N}$-doped submicron diameter carbon tubes derived from polypyrrole (PPy) precursor represent a very promising functional material. They have many advantages, especially due to the effects of heteroatom defects. The nitrogen species which they contain can promote pseudo-capacitive mutual effects between the nitrogen-containing functional groups and the electrolyte ions, in these respects as boosting surface wettability, electronic conductivity, capacity, etc. From another aspect, $\mathrm{N}$-doped carbon tubes with three-dimensional (3-D) structure as a matrix not only provide effective transport pathways for charge carriers to shorten ion/electron diffusion distances and good structural robustness to relieve electrode collapse due to the huge volume changes during cycling, but also enhance the diffusion of electrolyte into interior space in the composite to facilitate the interfacial reactions, as well as providing adequate access for fast $\mathrm{Na}^{+}$ transport.

There are some reports that make use of $\mathrm{N}$-doped carbon as a conducting polymer and mechanical buffer to enhance the electrochemical properties of carbon-based Na-storage anodes. ${ }^{33-36}$ Coating Sn nanoparticles onto N-doped carbon tubes to fabricate Sn-based anode material for SIBs has not yet been reported. Here, we report a user-friendly hydrothermal method taking N-doped carbon tubes as the matrix to anchor the Sn nanoparticles onto its surfaces and obtain C@Sn@N-doped carbon nanotube composites. In the first step, the precursor $\mathrm{SnO}_{2} @ \mathrm{~N}-$ doped carbon was obtained via a hydrothermal approach. In the as-prepared product, $\mathrm{SnO}_{2}$ nanoparticles were loaded homogeneously on the N-doped carbon framework. Next, resorcinol- 
formaldehyde resin as carbon source was deposited on the surface of the $\mathrm{SnO}_{2} @ \mathrm{~N}$-doped carbon and, then pyrolyzed to finish the carbon coating process. Here, the coated carbon can play two roles. Firstly, it can play the role of a dispersing agent to prevent the agglomeration of $\mathrm{Sn}$ nanoparticles, when $\mathrm{SnO}_{2}$ is reduced by $\mathrm{H}_{2}$. On the other hand, it provides a good tensile force to alleviate the volume expansion of Sn nanoparticles during continuous sodiation/desodiation processes, thereby helping to improve the cycling stability. In the composites, the surfaces of Ndoped carbon nanotubes are covered with evenly distributed carbon-coated Sn nanoparticles. The obtained 3-D C@Sn@N-doped carbon tube network displayed the good reversible capacity of $398.4 \mathrm{mAh} \mathrm{g}^{-1}$ on discharging at $100 \mathrm{~mA} \mathrm{~g}^{-1}$ with capacity retention of $67.3 \%$ and very high Coulombic efficiency of $99.7 \%$ after 150 cycles. Meanwhile, good rate capability was also obtained, based on varying the current density from $50 \mathrm{~mA} \mathrm{~g}^{-1}$ to $2 \mathrm{~A} \mathrm{~g}^{-1}$ during cycling.

\section{METHODS SECTION}

\section{Synthesis of N-doped carbon tubes}

The N-doped carbon tubes were prepared by pyrolyzing the precursor polypyrrole (PPy). The synthesis of PPy was carried out by the method in a previous report ${ }^{37}$ with some modifications. Firstly, $65 \mathrm{mg}$ methyl orange (MO) was dissolved in $100 \mathrm{ml}$ deionized water, and then $1.25 \mathrm{~g}$ of $\mathrm{FeCl}_{3}$ was added into the solution under constant stirring. Subsequently, an obvious flocculent precipitate appeared. Then, $0.3 \mathrm{~g}$ of pyrrole monomer was added into the mixture, which was stirred overnight in ambient air. After that, the PPy precipitate was centrifuged with distilled water and ethanol, up to the filter liquor was colorless and neutral. Soon afterwards, the precipitate was placed in a ceramic boat and moved into a tube furnace. The tube was heated to $100{ }^{\circ} \mathrm{C}$ at a heating rate of $2^{\circ} \mathrm{C} /$ min under argon atmosphere and kept at that temperature for $8 \mathrm{~h}$. 
Then, the tube was heated to $600{ }^{\circ} \mathrm{C}$ with a heating rate of $5{ }^{\circ} \mathrm{C} / \mathrm{min}$ and maintained at that temperature for $4 \mathrm{~h}$. Finally, the N-doped carbon tubes were obtained.

\section{Preparation of the $\mathrm{C} @ \mathrm{Sn} @ \mathrm{~N}$-doped carbon nanocomposites}

\section{Synthesis of the precursor $\mathrm{SnO}_{2} @ \mathrm{~N}$-doped carbon composites.}

In a typical procedure, $0.1 \mathrm{~g} \mathrm{~N}$-doped carbon was dispersed into $30 \mathrm{ml}$ of ethanol undergoing ultrasonic processing for $0.5 \mathrm{~h}$. Then, $0.025 \mathrm{~g}$ urea and $0.03 \mathrm{~g}$ hexamethylenetetramine (HMTA) were added into this solution under continued ultrasonic treatment for $15 \mathrm{~min}$. Subsequently, $0.1 \mathrm{~g} \mathrm{\textrm {SnCl } _ { 2 }} \cdot 2 \mathrm{H}_{2} \mathrm{O}$ was put into the before-mentioned mixture and stirred for $0.5 \mathrm{~h}$. Then, the miscible liquid was transferred into a Teflon-lined autoclave. Where it was quickly heated to 120 ${ }^{\circ} \mathrm{C}$ and kept at that temperature for $10 \mathrm{~h}$. The autoclave was naturally cooled down to the ambient temperature, and deionized water and ethanol were employed to wash the precipitate several times. The precipitate was dried in a vacuum oven at $60{ }^{\circ} \mathrm{C}$ overnight, and the final product (denoted as $\mathrm{SnO}_{2} @ \mathrm{~N}-$ doped carbon-I) was obtained. SnO $2 @ \mathrm{~N}-$ doped carbon-II and $\mathrm{SnO}_{2} @ \mathrm{~N}-$ doped carbon-III were prepared by adjusting the weight of $\mathrm{SnCl}_{2} \bullet 2 \mathrm{H}_{2} \mathrm{O}$ to $0.15 \mathrm{~g}$ or $0.2 \mathrm{~g}$, respectively.

\section{Preparation of the $\mathrm{C} @ \mathrm{Sn} @ \mathbf{N}$-doped carbon nanocomposites.}

$0.1 \mathrm{~g}$ of $\mathrm{SnO}_{2} @ \mathrm{~N}$-doped carbon-I was dispersed in $50 \mathrm{ml}$ deionized water under stirring. $5 \mathrm{mg}$ of cetyl-trimethylammonium bromide (CTAB) along with $0.5 \mathrm{ml}$ of $\mathrm{NH}_{3} \cdot \mathrm{H}_{2} \mathrm{O}, 28 \%$ solution, were added to the first solution and vigorously stirred for 20 mins. Next, $80 \mu \mathrm{L}$ formaldehyde solution $\left(37 \%\right.$ wt $\%$ in $\left.\mathrm{H}_{2} \mathrm{O}\right)$ and $60 \mathrm{mg}$ resorcinol were put into the solution and stirred overnight. After that, the precipitate was centrifuged and washed with ethanol three times. The precipitate was then moved into a tube furnace for carbonization. The sample was heated to 350 ${ }^{\circ} \mathrm{C}$ with a heating rate of $1 \% / \mathrm{min}$ under $\mathrm{N}_{2}$ atmosphere and kept at that temperature for $2 \mathrm{~h}$, then 
heated to $600{ }^{\circ} \mathrm{C}$ for $4 \mathrm{~h}$ with the same heating rate. When the temperature was cooled down to $550{ }^{\circ} \mathrm{C}$ at the end of the $4 \mathrm{~h}$, the protection gas was changed to $5 \% \mathrm{Ar} / \mathrm{H}_{2}$, and the sample was kept under those conditions for 2 h. Then, the final composite (denoted as C@Sn@N-doped carbon-I) was collected when the temperature of the tube furnace was reduced to room temperature. C@Sn@N-doped carbon-II and C@Sn@N-doped carbon-III were also prepared from the $\mathrm{SnO}_{2} @ \mathrm{~N}$-doped carbon-II or $\mathrm{SnO}_{2} @ \mathrm{~N}$-doped carbon-III by the same procedure, respectively. The above preparation processes are clearly displayed in Scheme 1.

\section{Materials Characterization}

$\mathrm{X}$-ray powder diffraction (XRD ; GBC MMA), with the diffractometer configured with $\mathrm{Cu} \mathrm{K} \alpha$ radiation at a scanning speed of $2^{\circ} \mathrm{min}^{-1}$, was used to evaluate the structural changes between the precursors and the as-prepared C@Sn@N-doped carbon composites. The content of Sn in the composites was measured through thermogravimetric analysis (TGA; Mettler Toledo TGA/DSC) carried out from $50{ }^{\circ} \mathrm{C}$ to $800{ }^{\circ} \mathrm{C}$ at a heating rate of $5{ }^{\circ} \mathrm{C} \min ^{-1}$ in air. X-ray photoelectron spectroscopy (XPS; SPECS PHOIBOS 100 Analyzer), using the spectrometer installed in a high-

vacuum chamber with the base pressure below $10^{-8} \mathrm{mbar}$, and the X-ray excitation generated by $\mathrm{Al} \mathrm{K \alpha}$ radiation at the high voltage of $12 \mathrm{kV}$ and power of $120 \mathrm{~W}$ was employed to identify the valence state of the $\mathrm{Sn}$ in the composites. The Casa XPS 2.3.15 software package was used to analyze the data obtained. All spectra were calibrated by $\mathrm{C}_{1 \mathrm{~s}}=284.6 \mathrm{eV}$. The morphology of the samples was surveyed by field emission scanning electron microscopy (FESEM; JEOL JSM7500FA) and high resolution transmission electron microscopy (HRTEM; JEOL JSM-2010).

\section{Electrochemical Measurements}

C@Sn@N-doped carbon composite (80wt\%) was mixed with acetylene black (10 wt \%) and carboxymethyl cellulose binder (10 wt\%) to prepare the working electrode slurry. The slurry was 
casted onto copper foil substrates, followed by drying in a vacuum oven overnight at $80{ }^{\circ} \mathrm{C}$. The mass loading of the active material in the electrode film was about $1.2 \mathrm{mg} \mathrm{cm}^{-2} .1 \mathrm{M} \mathrm{NaClO}_{4}$ dissolved in a solution of ethylene carbonate (EC) and dimethyl carbonate (DEC) $(1: 1 \mathrm{v} / \mathrm{v})$ containing 5\% (by weight) addition of fluoroethylene carbonate (FEC) served as electrolyte. The electrochemical performance testing was carried out via 2032-type coin cells. All the cells were assembled in an argon-filled glove box and measured under ambient conditions. Galvanostatic charge-discharge measurements were carried out via a Land Test System in the cut-off voltage range of $0.01-1.5 \mathrm{~V}\left(\mathrm{vs} . \mathrm{Na} / \mathrm{Na}^{+}\right.$) at current density of $100 \mathrm{~mA} \mathrm{~g}^{-1}$. The capacity was calculated based on the weight of the whole composite. Cyclic voltammetry and electrochemical impedance testing were carried out via a Biologic VMP-3 electrochemical workstation in the voltage range of $0.005 \mathrm{~V}-2.5 \mathrm{~V}$ (vs. Na/Na ${ }^{+}$) with a scanning rate of $0.1 \mathrm{mV} \mathrm{s}^{-1}$. Electrochemical impedance spectroscopy (EIS) was conducted using a CHI 660B electrochemical workstation.

\section{RESULTS AND DISCUSSION}

The successful preparation of the C@Sn@N-doped carbon nanocomposites is evidenced by XRD (Fig.1a). The XRD pattern of N-doped carbon shows a diffraction peak at $24.5^{\circ}$, reflecting to $d$-spacing of $0.36 \mathrm{~nm}$, which comes close to $0.34 \mathrm{~nm}$, i.e., the $d_{002}$ plane spacing in graphite. ${ }^{37}$ The XRD pattern of pure $\mathrm{Sn}$ is characterized by several peaks that can be assigned to $\beta$-metallic Sn with a tetragonal structure (JCPDS card no. 04-0673). In the three composites, C@Sn@Ndoped carbon-I, C@Sn@N-doped carbon-II, and C@Sn@N-doped carbon-III, we find that the sharp diffraction peaks appear in the same positions as for pure Sn. Meanwhile, the characteristic peak of N-doped carbon is no longer visible, which could be attributed to the Sn nanoparticles that cover the surfaces of N-doped carbon. 
To quantify the amount of Sn in the C@Sn@N-doped carbon composites, thermogravimetric analysis (TGA) was conducted in air. From the TGA curves shown in Fig.1b and 1c, it can be found that pure Sn shows a weight increase of $126.95 \%$, which is very consistent with the following reaction: $\mathrm{Sn}+\mathrm{O}_{2} \longrightarrow \mathrm{SnO}_{2}$. The $\mathrm{N}$-doped carbon was easily burned out, and only $1.8 \%$ residue was left. This amount could be neglected in determining the Sn content of the composites. From the curves of the three composites shown in Fig.1c, we find that all the samples display weight loss in the temperature range from 300 to $550{ }^{\circ} \mathrm{C}$, which is in conformity with the oxidation of $\mathrm{N}$-doped carbon. There were some differences between the composites and the N-doped carbon in the starting temperature of the weight loss. This phenomenon could be due to the large amount of Sn loaded onto the N-doped carbon, which postponed the N-doped carbon oxidation process. From $550^{\circ} \mathrm{C}$ onwards, the weight increase began, which meant that the oxidation of Sn occurred simultaneously. Based on the results of Fig. 1b, we calculated that the amounts of Sn in C@Sn@N-doped carbon-I, C@Sn@N-doped carbon-II, and C@Sn@N-doped carbon-III \% were $50.3 \%, 62.6 \%$, and $70.7 \%$, respectively.

To measure the interactions among the N-doped carbon, the Sn, and the C@Sn@N-doped carbon, the chemical status of elements was analysed via X-ray photoelectron spectroscopy (XPS). By comparing Fig. 2a and 2e, we can find an obvious change in the Sn peak from Ndoped carbon to the composites. All the peaks for C, N, and Sn in C@Sn@N-doped carbon-II appear in the XPS survey spectrum. The $\mathrm{Sn}_{3 \mathrm{~d}} \mathrm{XPS}$ spectrum of Sn and C@Sn@N-doped carbonII were obtained to analyse the change in the chemical state of Sn before and after reduction.

In Fig. $2 \mathrm{c}$ and $2 \mathrm{~g}$, by comparing the positions of the two peaks for $\mathrm{Sn}_{3 \mathrm{~d}}$ for pure $\mathrm{Sn}$ and the composite, it is clear that they all display the same binding energy interval of $8 \mathrm{eV}$, which is in accordance with the energy splitting of $\mathrm{Sn}^{38}{ }^{38}$ For bare $\mathrm{Sn}$, the peaks found at $485.9 \mathrm{eV}$ and 494.9 
$\mathrm{eV}$ correspond to the $3 \mathrm{~d}_{5 / 2}$ and $3 \mathrm{~d}_{3 / 2}$ peaks of $\mathrm{Sn}^{39}$ When $\mathrm{Sn}$ was coated with N-doped carbon, the $\mathrm{Sn}_{3 \mathrm{~d}}$ peaks were shifted to higher binding energies, i.e., $486.3 \mathrm{eV}$ and $495.3 \mathrm{eV}$. These changes in the peak positions were obviously affected by the presence of N-doped carbon, and in terms of conductivity, the bare $\mathrm{Sn}$ is better than the N-doped carbon. ${ }^{40,41}$ In the $\mathrm{C}_{1 \mathrm{~s}}$ spectra for Ndoped carbon (Fig.2d) and C@Sn@N-doped carbon-II (Fig.2h), no new peaks appeared, which means that $\mathrm{C}-\mathrm{Sn}$ bonds do not exist. These spectra also showed that the peaks corresponding to $\mathrm{C}=\mathrm{N}, \mathrm{C}-\mathrm{OH}, \mathrm{O}=\mathrm{C}-\mathrm{N}$ in $\mathrm{C}_{1 \mathrm{~s}}$ from $\mathrm{N}$-doped carbon to $\mathrm{C} @ \mathrm{Sn} @ \mathrm{~N}$-doped carbon-II shifting to higher binder energy. There also showed the peaks corresponding to $\mathrm{C}=\mathrm{N}, \mathrm{C}-\mathrm{OH}$, and $\mathrm{O}=\mathrm{C}-\mathrm{N}$ in $\mathrm{C}_{1 \mathrm{~s}}$ were shifted to higher binding energy from N-doped carbon to C@Sn@N-doped carbon-II. This was mainly because when C@Sn particles were coated with N-doped carbon, the electronic conductivity of the C@Sn@N-doped carbon-II was lower than that of the N-doped carbon shown on Fig. 6f. Similar phenomena can be found in a previous report. ${ }^{40}$ From the $\mathrm{N}_{1 \mathrm{~s}}$ spectrum for N-doped carbon (Fig.2b) and C@Sn@N-doped carbon-II (Fig.2f), we can see that pyridinic (N-6), pyrrolic/pyridone (N-5), and quaternary (N-Q) nitrogen are all present. Table 1 displays the content ratio changes for pyridinic $\mathrm{N}$, pyrrolic $\mathrm{N}$, and quaternary $\mathrm{N}$ from $\mathrm{N}$-doped carbon to C@Sn@N-doped carbon respectively. These results reveal that no chemical reaction took place in the synthesis process and that all components are bound together by van der Waals forces.

The morphology changes from $\mathrm{N}$-doped carbon to the precursor $\mathrm{SnO}_{2} @ \mathrm{~N}$-doped carbon composites were investigated by scanning electron microscopy (SEM). The image of N-doped carbon shows strip-like 3-D structured tubes with relatively smooth surfaces in Fig.3a and 3b. For $\mathrm{SnO}_{2} @ \mathrm{~N}$-doped carbon-I, $\mathrm{SnO}_{2} @ \mathrm{~N}$-doped carbon-II, and $\mathrm{SnO}_{2} @ \mathrm{~N}$-doped carbon-III, in Fig.3c, $3 \mathrm{e}$, and $3 \mathrm{~g}$, rough surfaces can be easily found, and the diameter of the composite tubes 
has obviously increased compared with $\mathrm{N}$-doped carbon. These images clearly demonstrate that the $\mathrm{SnO}_{2}$ nanoparticles are uniformly distributed on the $\mathrm{N}$-doped carbon tubes.

Fig. 3 also displays the differences in morphology between $\mathrm{SnO}_{2} @ \mathrm{~N}$-doped carbon and C@Sn@N-doped carbon composites. By comparing the images shown in Fig.3d, 3f, and 3h, we can find that after the resorcinol-formaldehyde (RF) coating and the carbonization in the following reduction, the surface of the C@Sn@N-doped carbon composite has become much smoother than for the precursor $\mathrm{SnO}_{2} @ \mathrm{~N}$-doped carbon. This phenomenon is due to the very small carbon nanoparticles covering the surfaces of the Sn particles. The size of the carbon particles is much smaller than that of the $\mathrm{SnO}_{2}$ particles.

The homogeneity of the element composition was also measured by energy dispersive X-ray spectroscopy (EDS) mapping. From the elemental mapping images of C, N, and $\mathrm{Sn}$ as displayed in Fig. 4, it can be clearly observed that there is a uniform distribution of Sn on the N-doped carbon tubes.

The changes in the structure between the N-doped carbon and the C@Sn@N-doped carbon composites were further investigated by using transmission electron microscopy (TEM). As displayed in Fig. 5a, the N-doped carbon tube is open on one end and sealed on the other end. This property is beneficial for stable anchoring of the Sn particles on the tube. Before the coating with $\mathrm{Sn}$, the diameter of the $\mathrm{N}$-doped carbon tubes was no greater than $300 \mathrm{~nm}$. From the images of the three composites (Fig. 5b, 5c, and 5d), obvious changes in the diameter of the tubes can be observed. The diameters for the three samples were significantly increased to about $350 \mathrm{~nm}, 470$ $\mathrm{nm}$, and $640 \mathrm{~nm}$, respectively. Fig. 5e shows the (200) and (301) lattice fringes, which were measured to have spacing of 0.29 and $0.165 \mathrm{~nm}$, respectively. Furthermore, pure phase Sn can be 
identified on the selected area electron diffraction (SAED) pattern (Fig. 5f), which is indexed to the diffraction peaks of the (200), and (301) planes as shown on the XRD patterns.

The cycling performances of the C@Sn@N-doped carbon-I, C@Sn@N-doped carbon-II, and C@Sn@N-doped carbon-III composites at a current density of $100 \mathrm{~mA} \mathrm{~g}^{-1}$, within a cut-off voltage range of $0.01-1.5 \mathrm{~V}$ (vs. $\mathrm{Na} / \mathrm{Na}^{+}$) over 150 cycles, are displayed in Fig.6a. The reversible charge capacities of the C@Sn@N-doped carbon-I, C@Sn@N-doped carbon-II, and C@Sn@Ndoped carbon-III composites are 303.5, 398.4, and $340 \mathrm{mAh} \mathrm{g}^{-1}$, respectively, after 150 cycles, corresponding to $55.8 \%, 67.3 \%$, and $50.3 \%$ of their initial charge capacities. From this trend, we can find that $\mathrm{C} @ \mathrm{Sn} @ \mathrm{~N}$-doped carbon-II has the best reversible charge capacity and capacity retention. In the case of $\mathrm{C} @ \mathrm{Sn} @ \mathrm{~N}$-doped carbon-I, due to the lesser amount of Sn, the charge capacity is the smallest, but its' capacity retention is higher than that of C@Sn@N-doped carbon-III. As for C@Sn@N-doped carbon-III, even though it has the biggest amount of Sn and the highest initial charge capacity, the capacity fading is apparent. This phenomenon can be attributed to the agglomeration caused by the presence of more Sn particles. In this regard, the coating carbon and the N-doped carbon also take on indispensable roles. First, the coating carbon layer can hold back the agglomeration of Sn nanoparticles and provide a good tensile force to alleviate the volume expansion of Sn nanoparticles during the continuous sodiation/desodiation processes. On the other hand, the N-doped carbon matrix, due to its' porous structure with large surface area ensures the uniform dispersion of Sn nanoparticles. At the same time, N-doped carbon with its' 3-D structure also provides short ion/electron pathways to promote the diffusion of the $\mathrm{Na}^{+}$ion into the internal spaces of the composites. Furthermore, the good structural robustness of $\mathrm{N}$-doped carbon is very useful for accommodating the huge volume changes in the charging/discharging process and mitigating the pulverization of the electrode. Therefore, the 
best reversible charge capacity and capacity retention come from the optimum ratio of Sn with respect to the carbon layer and N-doped carbon.

To distinguish the contributions of the N-doped carbon substrate and the bare $\mathrm{Sn}$ to the electrochemical properties of the $\mathrm{C} @ \mathrm{Sn} @ \mathrm{~N}-$ doped carbon composites, the three samples were also tested with the same current density and cut-off voltage, as shown in Fig. 6b. The preserved capacity of the N-doped carbon was about $125.6 \mathrm{~mA} \mathrm{~h} \mathrm{~g}^{-1}$ after 150 cycles. The contribution of pure Sn particles to the capacity of the $\mathrm{C} @ \mathrm{Sn} @ \mathrm{~N}$-doped carbon composites can be neglected due to their strong agglomeration during cycling. In Fig.6b, we also find that the coulombic efficiency for C@Sn@N-doped carbon-II is close to 100\%, starting from the second cycle, demonstrating that electrons/ $\mathrm{Na}$ ions were no longer being captured in parasitic reactions, which could be maintained by further electrolyte degeneration.

Furthermore, the rate capabilities of the C@Sn@N-doped carbon-I, C@Sn@N-doped carbonII, and C@Sn@N-doped carbon-III composites were investigated by augmenting the current density step by step from $50 \mathrm{~mA} \mathrm{~g}^{-1}$ up to $2 \mathrm{~A} \mathrm{~g}^{-1}$ and finally returning to $100 \mathrm{~mA} \mathrm{~g}^{-1}$. The cycling performances of all the composites with different current densities are shown in Fig.6c. In the case of $\mathrm{C} @ \mathrm{Sn} @ \mathrm{~N}$-doped carbon-I, the reversible charge capacity decreased from 610.6 $\left(50 \mathrm{~mA} \mathrm{~g}^{-1}\right)$, to $546.2\left(0.1 \mathrm{~A} \mathrm{~g}^{-1}\right), 437.2\left(0.2 \mathrm{~A} \mathrm{~g}^{-1}\right), 327.3\left(0.4 \mathrm{~A} \mathrm{~g}^{-1}\right), 233.6\left(0.8 \mathrm{~A} \mathrm{~g}^{-1}\right), 177.4$ (1 $\left.\mathrm{A} \mathrm{g}^{-1}\right)$, and $117.1 \mathrm{mAh} \mathrm{g}^{-1}\left(2 \mathrm{~A} \mathrm{~g}^{-1}\right)$, respectively, and then it increased to $559.1 \mathrm{mAh} \mathrm{g}^{-1}$ (recovering $99.9 \%$ of its initial capacity) after 70 cycles when the current density was returned to $0.1 \mathrm{~A} \mathrm{~g}^{-1}$. The rate capability of $\mathrm{C} @ \mathrm{Sn} @ \mathrm{~N}$-doped carbon-II displayed the highest reversible charge capacity among the composites. The values changed according to the following trend, $647.2\left(50 \mathrm{~mA} \mathrm{~g}^{-1}\right)$, to $579\left(0.1 \mathrm{~A} \mathrm{~g}^{-1}\right), 463.4\left(0.2 \mathrm{~A} \mathrm{~g}^{-1}\right), 347\left(0.4 \mathrm{~A} \mathrm{~g}^{-1}\right), 247.6\left(0.8 \mathrm{~A} \mathrm{~g}^{-1}\right), 188.1$ $\left(1 \mathrm{~A} \mathrm{~g}^{-1}\right)$, and $124.1 \mathrm{mAh} \mathrm{g}^{-1}\left(2 \mathrm{~A} \mathrm{~g}^{-1}\right)$. When the current density was returned to $0.1 \mathrm{~A} \mathrm{~g}^{-1}$, the 
capacity recovered to $592.8 \mathrm{mAh} \mathrm{g}^{-1}$ (regaining $99.9 \%$ of its initial capacity) after 70 cycles. As for C@Sn@N-doped carbon-III, it displayed much higher capacity at low current density. With increasing current rate, the capacity declined more quickly, and it showed very poor recovery capability compared to the other composites. The results are as follows: $758.1\left(50 \mathrm{~mA} \mathrm{~g}^{-1}\right)$, to $670.1\left(100 \mathrm{~mA} \mathrm{~g}^{-1}\right), 549.5\left(200 \mathrm{~mA} \mathrm{~g}^{-1}\right), 371.4\left(400 \mathrm{~mA} \mathrm{~g}^{-1}\right), 235.2\left(800 \mathrm{~mA} \mathrm{~g}^{-1}\right), 178.6\left(1 \mathrm{~A} \mathrm{~g}^{-}\right.$ $\left.{ }^{1}\right)$, and $117.9 \mathrm{mAh} \mathrm{g}^{-1}\left(2 \mathrm{~A} \mathrm{~g}^{-1}\right)$. After the current rate was restored to $0.1 \mathrm{~A} \mathrm{~g}^{-1}$, the capacity could only reach $436.5 \mathrm{mAh} \mathrm{g}^{-1}$ (very low capacity retention, recovering only $64.3 \%$ of its initial capacity) after 70 cycles.

A comparison of the performance of C@Sn@N-doped carbon with some C/Sn-based anode materials is presented in Table 2. From there, it can be seen that the overall performance of the C@Sn@N-doped carbon is very good in terms of reversible capacity $\left(398.4\right.$ mA h g ${ }^{-1}$ at 100 mA $\left.\mathrm{g}^{-1}\right)$, although it is not the very best performance.

Fig.6d displays the discharge-charge voltage profiles of the initial three cycles for C@Sn@Ndoped carbon-II. The $1^{\text {st }}$ cycle discharge and ${ }^{\text {nd }}$ cycle charge capacities of the C@Sn@N-doped carbon-II composite electrode are 1283.1 and $593.3 \mathrm{mAh} \mathrm{g}^{-1}$, respectively, delivering an initial coulombic efficiency of $46 \%$. This is believed to be due to the creation of a solid electrolyte interphase (SEI) film between the Sn nanoparticles and the electrolyte.

To analyze the electrochemical reactions occurring in the C@Sn@N-doped carbon-II electrode, cyclic voltammetry $(\mathrm{CV})$ was conducted. It can be observed in Fig. 6e, there is a cathodic slope from 1.38 to $1.05 \mathrm{~V}$ in the first negative scan, which is attributed to the interaction between $\mathrm{Na}^{+}$and the surface functional groups of carbon. ${ }^{31}$ In the following cathodic scan, a broad integrated peak starting at $0.75 \mathrm{~V}$ and ending at $0.3 \mathrm{~V}$ can be detected, which is assigned to the formation of the SEI layer, with the alloying between $\mathrm{Sn}$ and $\mathrm{Na}$ forming $\mathrm{NaSn}_{5}$ and, $\mathrm{NaSn}$, 
and promoting $\mathrm{Na}^{+}$insertion into carbon. The two weakly reductive peaks appearing at 0.2 and $0.01 \mathrm{~V}$ indicate the formation of $\mathrm{Na}_{9} \mathrm{Sn}_{4}$ and $\mathrm{Na}_{15} \mathrm{Sn}_{4} \cdot{ }^{42.43}$ In the following anodic scan, three well-defined oxidative peaks can be observed at $0.2,0.55$, and $0.7 \mathrm{~V}$, which are assigned to desodiation from $\mathrm{Na}_{9} \mathrm{Sn}_{4}, \mathrm{NaSn}$, and $\mathrm{NaSn}_{5}$, respectively. From the second cathodic scan, three dominant reduction peaks appearing at $0.75 \mathrm{~V}, 0.2 \mathrm{~V}$, and $0.01 \mathrm{~V}$ are considered to be due to the formation of $\mathrm{Na}_{x} \mathrm{Sn}, \mathrm{Na}_{9} \mathrm{Sn}_{4}$, and $\mathrm{Na}_{15} \mathrm{Sn}_{4} \cdot{ }^{44}$ The above analysis results are very similar to the results from the charge-discharge curves of the C@Sn@N-doped carbon-II electrode shown in Fig.6d.

By conducting electrochemical impedance spectroscopy (EIS), we further analysed the effects of N-doped carbon towards improving the cyclability of C@Sn@N-doped carbon electrode, which had better retention of electronic conductivity than the bare Sn electrode. Fig.6f. displays the Nyquist plots, with the insert showing the equivalent electrical circuit, wherein, the total resistance of the electrolyte and cell components is represented by $R_{i}$. The charge transfer resistance $\left(R_{c t}\right)$, appearing as the depressed semicircle in the high frequency range, reflects the impedance connected to the passage of the $\mathrm{Na}^{+}$ions through the film surface and the charge transfer between the active material and the electrolyte. The Warburg impedance $(W)$ can be found from the sloping line located in the low frequency region. It is attributed to the charge transfer due to sodium ion diffusion inside the active material or electrolyte. The constant phase element (CPE) is used to replace the pure capacitance. It can be observed that the charge transfer resistance $\left(R_{c t}\right)$ of bare Sn has changed significantly between the fresh electrode and after 150 cycles. The value increased from 230.3 to $906.9 \Omega$. This result is consistent with the changes in the morphology of the Sn electrode after cycling, as shown in Fig. $7 \mathrm{~b}$ and $7 \mathrm{~d}$, where the morphology of the bare Sn electrode after cycling features very obvious cracks. For C@Sn@N- 
doped carbon-II, the charge transfer resistance $\left(R_{c t}\right)$ changed slightly from 284.1 to $328.9 \Omega$ after experiencing cycling from the fresh cell to over 150 cycles. This small change demonstrates that the C@Sn@N-doped carbon-II electrode can maintain its electrical conductivity very well. As shown in Fig.7a and 7c, there are no obvious cracks in the C@Sn@N-doped carbon composite electrode after cycling, which is attributed to the 3-D structural features of C@Sn@N-doped carbon-II, which provides void space between the tubes that could withstand the large volume expansion during charging/discharging. Furthermore, the homogeneous distribution of $\mathrm{Sn}$ nanoparticles on the surface of the N-doped carbon matrix is also an important factor in providing homogeneity to the whole composite, so as to keep the electrochemical properties stable. The improved electrochemical performance of the C@Sn@N-doped carbon composites compared with pure Sn is due to the synergistic effects generated among the Sn nanoparticles, the carbon coating layer on the surfaces of the Sn nanoparticles and the N-doped carbon conductive matrix. Firstly, the Sn nanoparticles as the main active component are responsible for the main contribution to the high specific capacity. Secondly, the carbon coating layer on the $\mathrm{Sn}$ nanoparticles serves multiple functions: (i) The carbon coating layer acts as an adhesive interface to bind the Sn nanoparticles and the N-doped carbon network together to form a conducting matrix to improve the conductivity of the composite; (ii) The carbon coating layer can withstand the large volume expansion of the electrode in the process of cycling to maintain the integrity of the electrode; (iii) The carbon coating layer prevents agglomeration of Sn nanoparticles during cycling to improve cycling stability. Lastly, the N-doped carbon network with 3-D structure not only enables sufficient infiltration of electrolyte, but also provides more reactive sites arising from the nitrogen doping. ${ }^{45}$ Furthermore, the N-doped carbon can contribute capacity to the Naion batteries, as shown in Fig. 6b. Therefore, the C@Sn@N-doped carbon composites exhibit 
improved electrochemical performance, resulting from both the structure of the carbon coated $\mathrm{Sn}$ nanoparticles and the continuous 3-D reaction network formed by the N-doped carbon.

\section{CONCLUSIONS}

In summary, C@Sn@N-doped carbon composites were obtained with Sn particles confined in the framework of $\mathrm{N}$-doped carbon via an easy, convenient, and environmentally friendly approach. The 3-D structured C@Sn@N-doped carbon tube network exhibited good electrochemical properties as a candidate anode that could be applied in SIBs, in terms of its cycling performance (up to 150 cycles), with $99.7 \%$ coulombic efficiency and good rate capability. The initial charge capacity was restored to $99.7 \%$ after continuous current alteration

from $50 \mathrm{~mA} \mathrm{~g}^{-1}$ to $2 \mathrm{~A} \mathrm{~g}^{-1}$. The good experimental results are mainly attributed to the homogeneous distribution of carbon-encapsulated $\mathrm{Sn}$ nanoparticles on the N-doped carbon matrix with its distinct 3-D structure, which plays the role of alleviating the stress caused by the volume expansion of the electrode during the charge/discharge process. From another aspect, the carbon coating on the surfaces of the Sn nanoparticles can maintain the stability of the electrode structure by inhibiting the growth and agglomeration of Sn grains and reducing the polarization effect. Therefore, our results clearly demonstrate that the improved electrochemical performance of the $\mathrm{C} @ \mathrm{Sn} @ \mathrm{~N}$-doped carbon composites benefits from the synergistic effect generated among the carbon coated Sn nanoparticles and the N-doped carbon conductive matrix, which makes it possible to obtain the best utilization of $\mathrm{Na}^{+}$during insertion/extraction. 

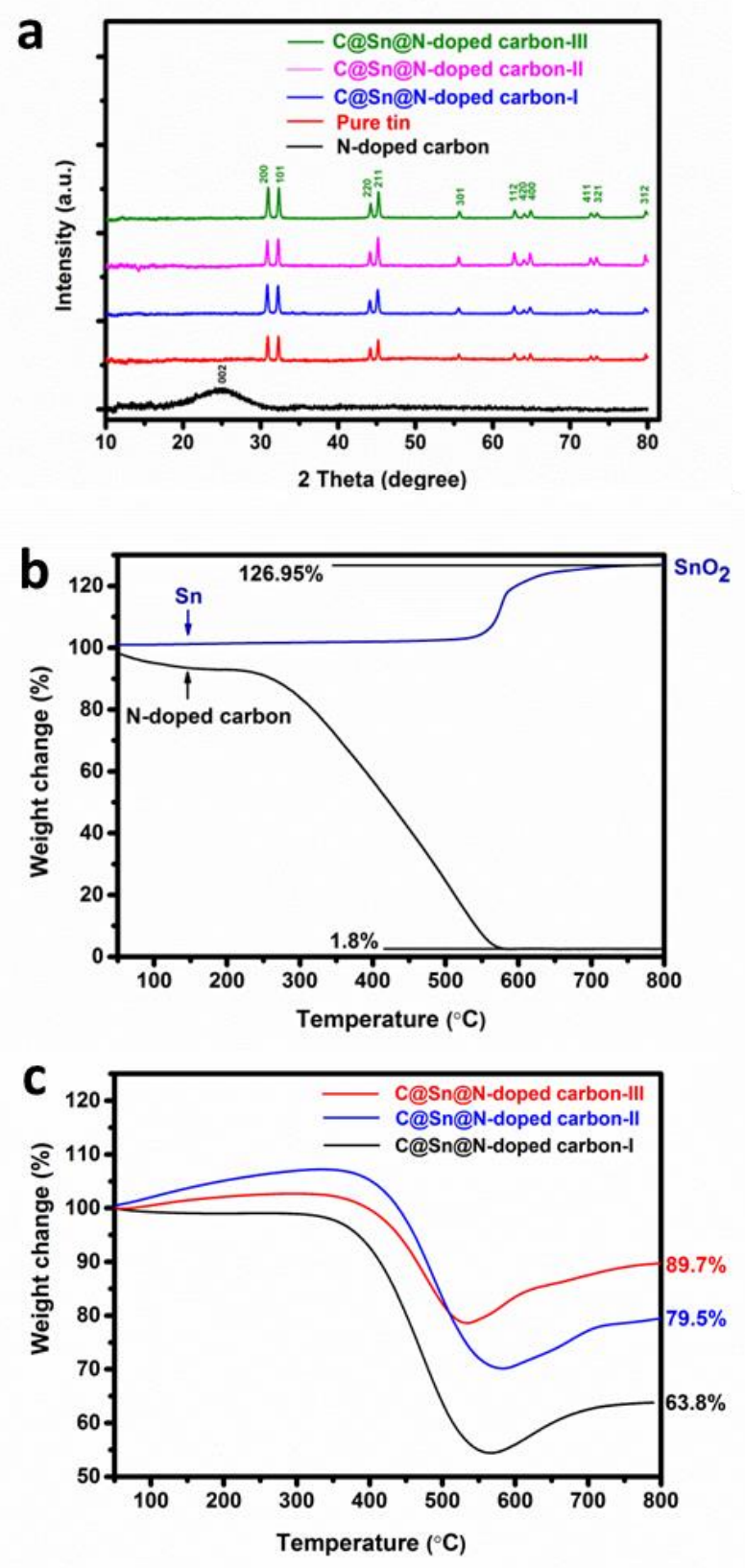

Figure 1. XRD patterns of all three samples along with pure tin and N-doped carbon (a). TGA curves of pure Sn particles and N-doped carbon in air (b), and of C@Sn@N-doped carbon composites in air (c). 

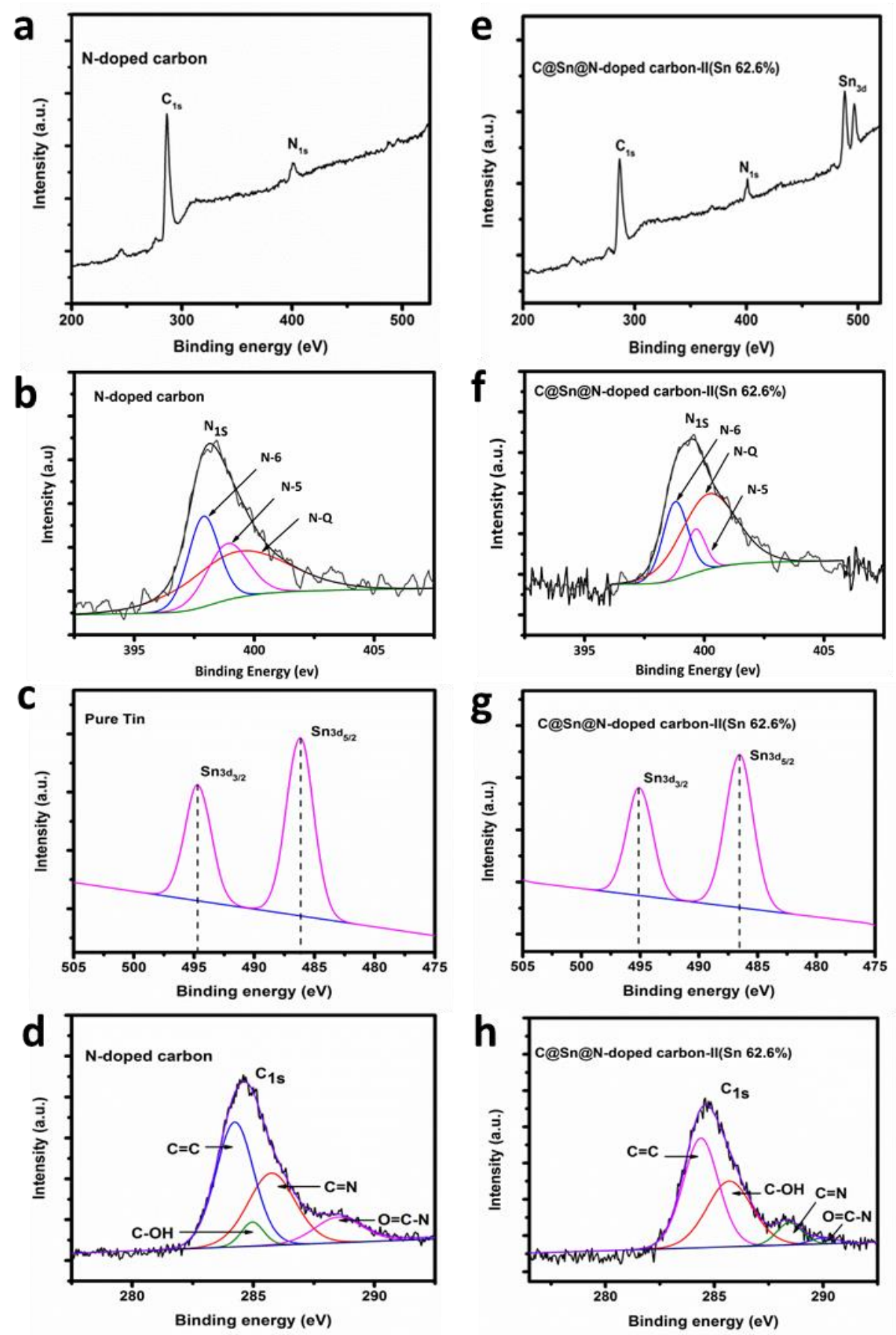

Figure 2. XPS survey spectra: (a) N-doped carbon, (e) C@Sn@N-doped carbon-II (Sn 62.6\%); XPS high resolution spectra: (b) $\mathrm{N}_{1 \mathrm{~s}}$ for $\mathrm{N}$-doped carbon, (f) $\mathrm{N}_{1 \mathrm{~s}}$ for $\mathrm{C} @ \mathrm{Sn} @ \mathrm{~N}$-doped carbon-II (Sn 62.6\%), (c) Sn $\mathrm{Sn}_{3 \mathrm{~d}}$ for pure Sn, (g) Sn $\mathrm{Sn}_{3 \mathrm{~d}}$ for C@Sn@N-doped carbon-II (Sn 62.6\%). (d) $\mathrm{C}_{1 \mathrm{~s}}$ for N-doped carbon, (h) $\quad \mathrm{C}_{1 \mathrm{~s}} \quad$ for $\quad \mathrm{C} @ \mathrm{Sn} @ \mathrm{~N}$-doped carbon-II $\quad$ (Sn62.6\%). 


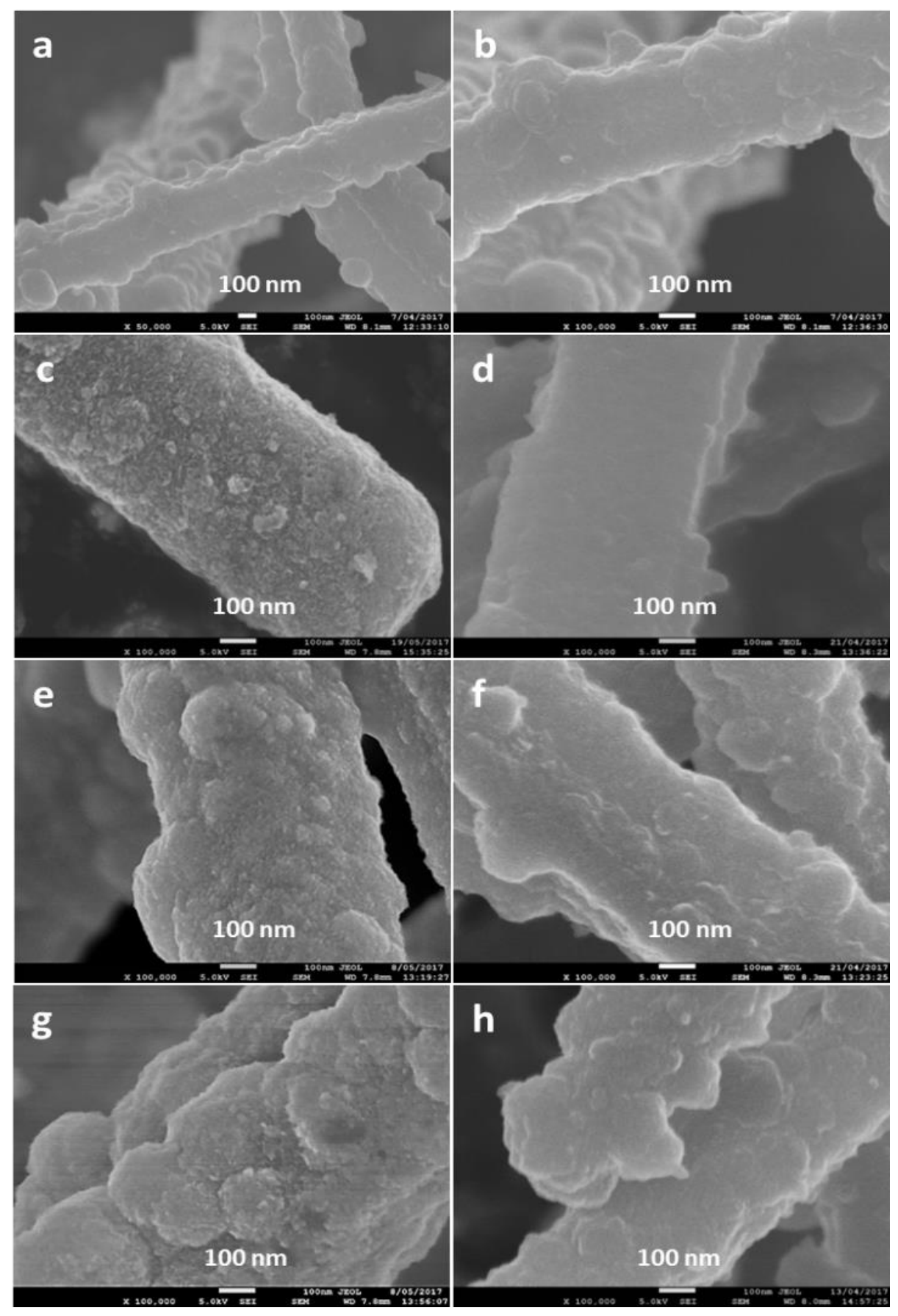

Figure 3. SEM images of (a,b) N-doped carbon at different magnifications, (c) $\mathrm{SnO}_{2} @ \mathrm{~N}$-doped carbon-I, (d)C@Sn@N-doped carbon-I (Sn 50.3\%), (e) $\mathrm{SnO}_{2} @ N$-doped carbon-II, (f)

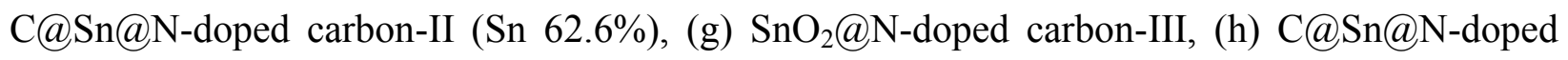
carbon-III (Sn70.7\%). 


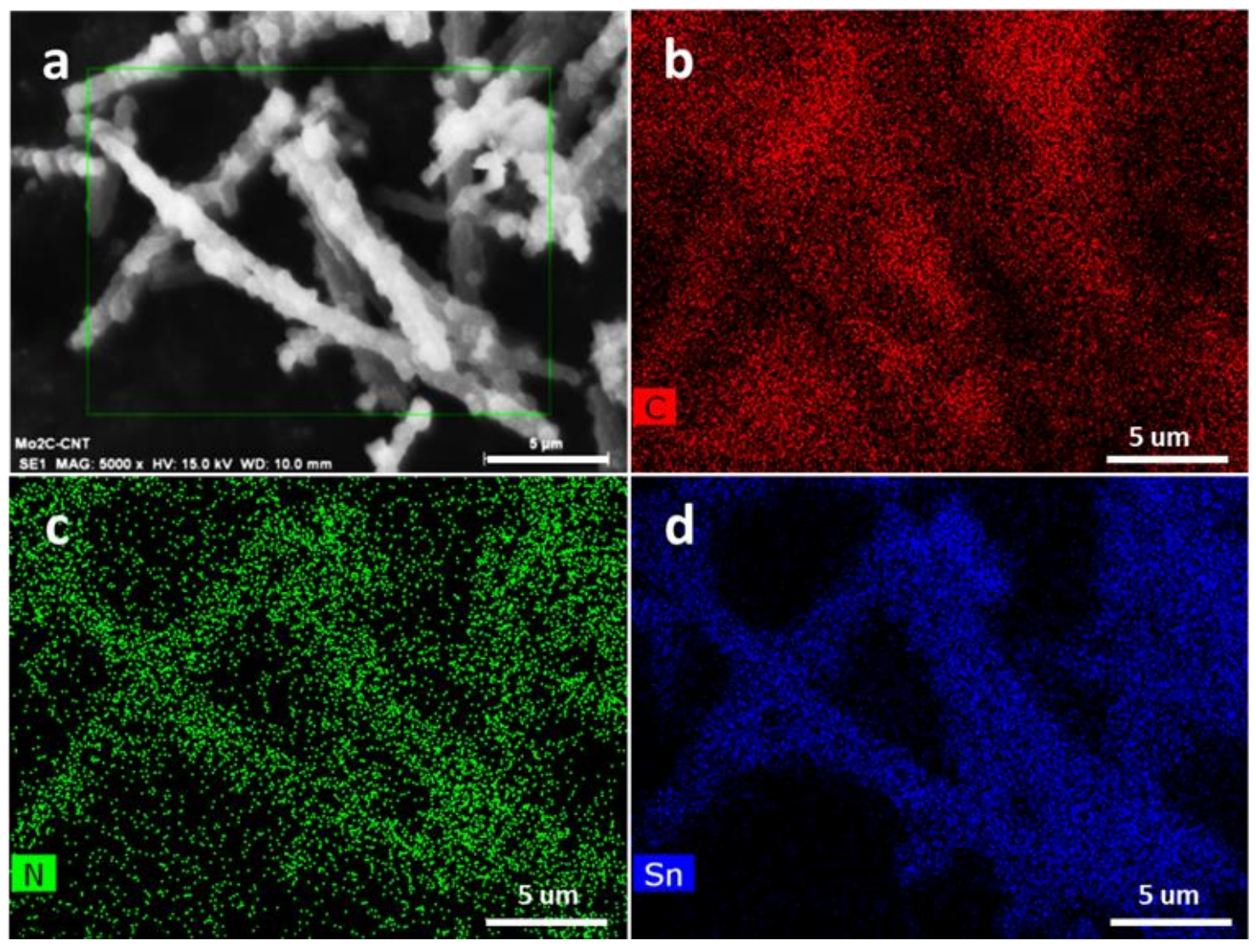

Figure 4. Dark field image of C@Sn@N-doped carbon-II (Sn 62.6\%) (a), corresponding EDS mappings of C (b), N (c), and Sn (d) in C@Sn@N-doped carbon-II (Sn 62.6\%). 


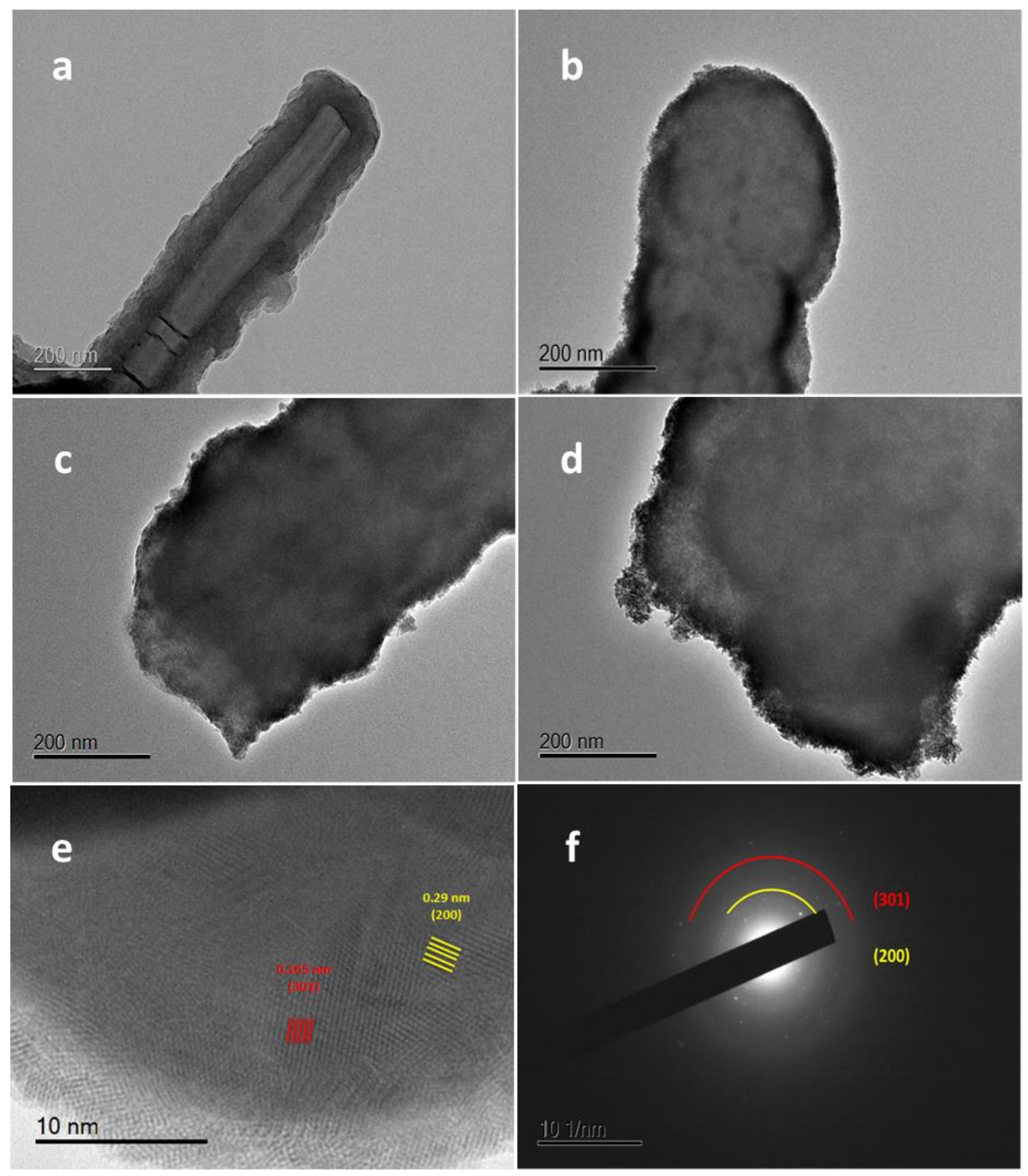

Figure 5. TEM image of $\mathrm{N}$-doped carbon tube (a), low magnification TEM images of C@Sn@N-doped carbon-I (Sn 50.3\%) (b), C@Sn@N-doped carbon-II (Sn 62.6\%) (c), C@Sn@N-doped carbon-III (Sn 70.7\%) (d), high magnification image (e) and SAED pattern (f) of C@Sn@N-doped carbon-II (Sn 62.6\%). 

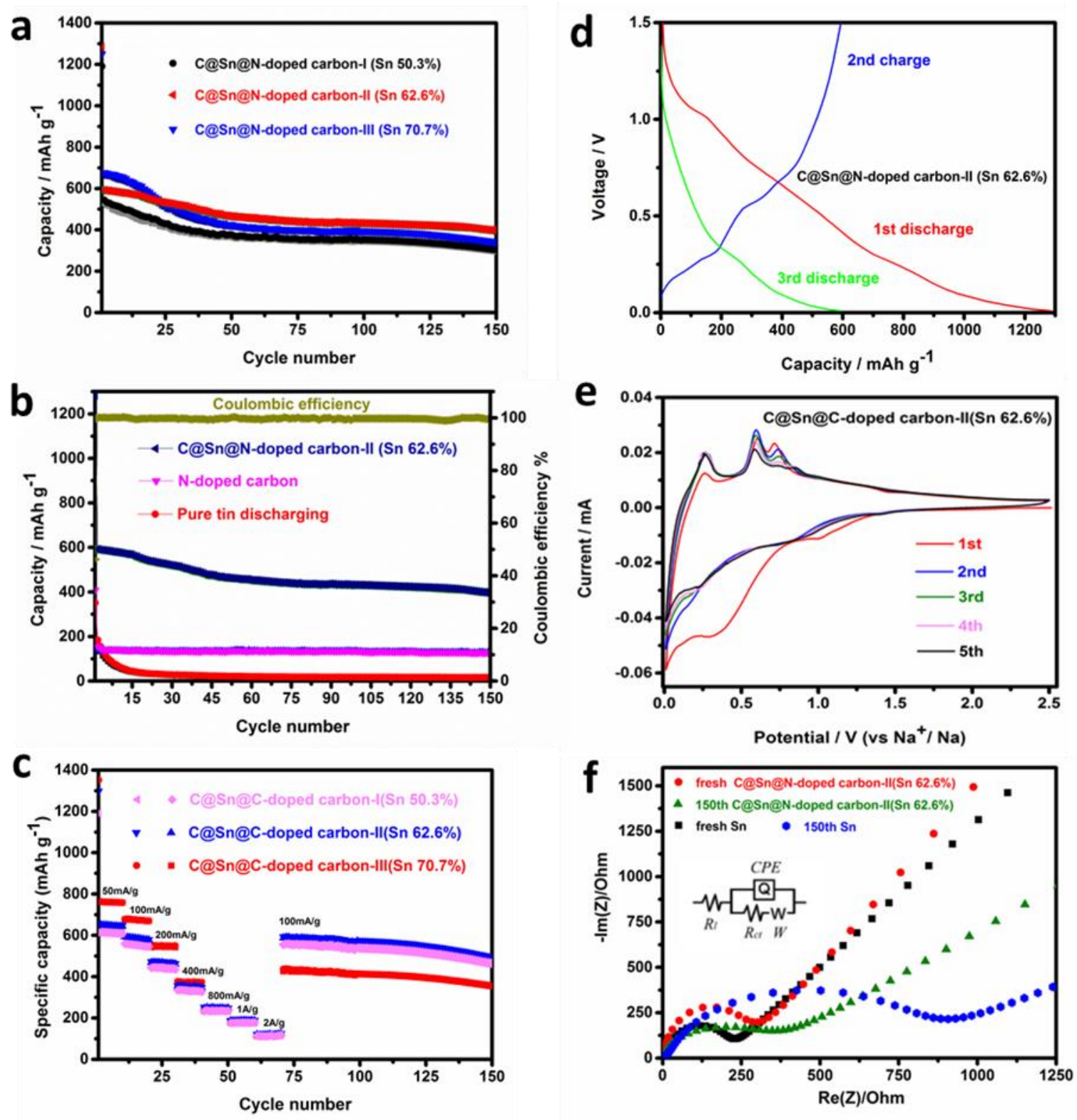

Figure 6. Cycling performances of the C@Sn@N-doped carbon composites (a); Cycling performance comparison of C@Sn@N-doped carbon-II (Sn 62.6\%), N-doped carbon, and pure Sn particles (b); Rate capability of C@Sn@N-doped carbon composites (c); Charge-discharge curves for the first 3 cycles of C@Sn@N-doped carbon-II (Sn 62.6\%)(d); Cyclic voltammograms for the first 5 cycles of C@Sn@N-doped carbon-II (Sn 62.6\%) (e); Impedance plots of fresh N-doped carbon, C@Sn@N-doped carbon-II (Sn 62.6\%), and bare Sn particle electrodes, and plots after 150 cycles. Inset is the equivalent circuit model for the analysis (f). 


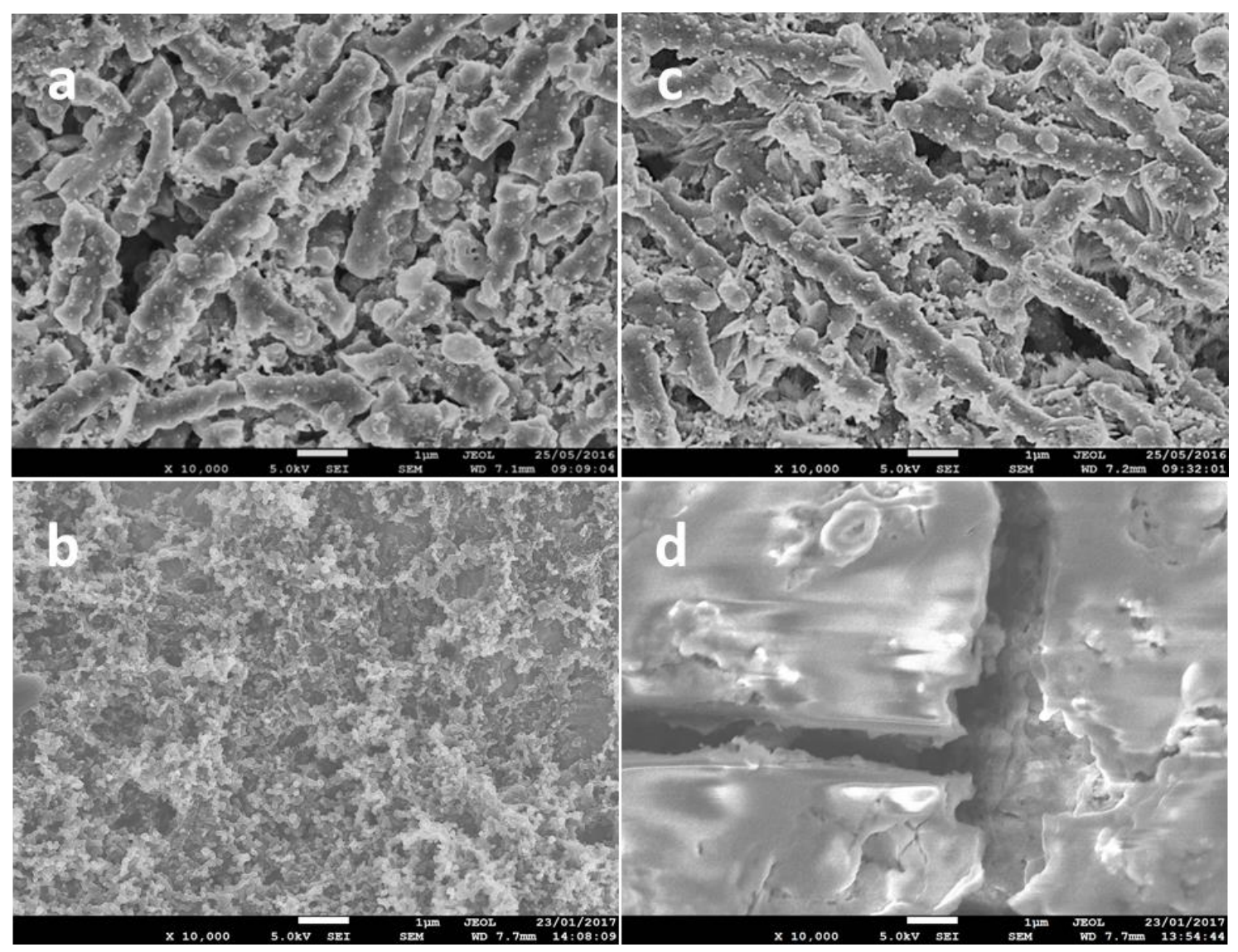

Figure 7. SEM images of C@Sn@N-doped carbon-II (Sn 62.6\%) composite electrodes before the charge/discharge testing (a), after 150 charge/discharge cycles (c); Fresh Sn particle electrode (b), and Sn particle electrode after 150 cycles (d). 


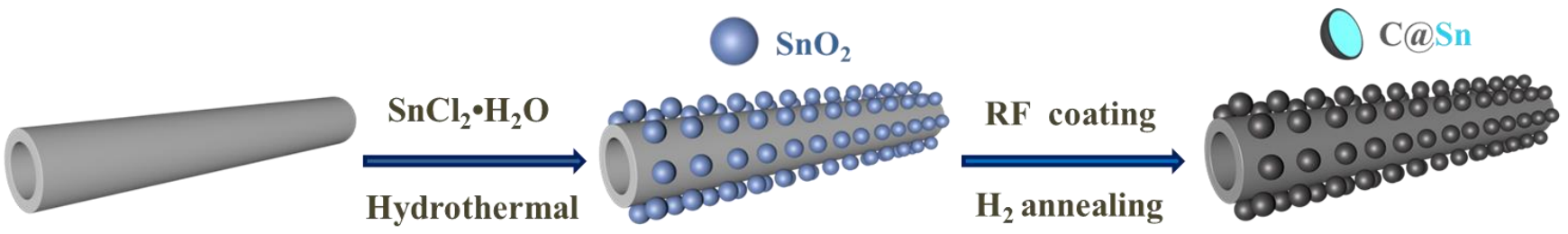

Scheme 1. Schematic illustration of the synthesis processes for the fabrication of C@Sn@Ndoped carbon. 
Table 1. Nitrogen configurations derived from peak analysis of $\mathrm{N} 1 \mathrm{~s}$ in $\mathrm{N}$-doped carbon and C@Sn@N-doped carbon (Sn 62.6\%)

\begin{tabular}{lccc} 
Sample & Quaternary $\%$ & Pyrrolic $\%$ & Pyridinic \% \\
\hline N-doped carbon & 52.32 & 28.31 & 19.37 \\
C@Sn@N-doped carbon-II & 56.26 & 20.13 & 23.61
\end{tabular}

(Sn 62.6\%) 
Table 2. Performance comparison of our current work with previously published reports related to $\mathrm{C} / \mathrm{Sn}$-based anode materials for SIBs.

\begin{tabular}{|c|c|c|c|c|}
\hline Materials & Rate performance & Reversible capacity & Cycles & Ref. \\
\hline $\mathrm{Sn} / \mathrm{Cu}$ Nanocomposite & $\begin{array}{l}126 \mathrm{~mA} \mathrm{~h} \mathrm{~g}^{-1} \\
\text { at } 1.69 \mathrm{~A} \mathrm{~g}^{-1}\end{array}$ & $\begin{array}{l}420 \mathrm{~mA} \mathrm{~h} \mathrm{~g}^{-1} \\
\text { at } 169 \mathrm{~mA} \mathrm{~g}^{-1}\end{array}$ & 100 & [28] \\
\hline $\mathrm{C} / \mathrm{Sn} / \mathrm{Ni} / \mathrm{TMV}$ & at $50 \mathrm{~mA} \mathrm{~g}^{-1}$ & $405 \mathrm{~mA} \mathrm{~h} \mathrm{~g}^{-1}$ & 150 & [29] \\
\hline Sn@Wood fiber & at $84 \mathrm{~mA} \mathrm{~g}^{-1}$ & $145 \mathrm{~mA} \mathrm{~h} \mathrm{~g}^{-1}$ & 400 & {$[30]$} \\
\hline Sn@CNT-CP & $\begin{array}{l}299 \mathrm{uA} \mathrm{h} \mathrm{cm}^{-2} \\
\text { at } 1 \mathrm{~mA} \mathrm{~cm}^{-2}\end{array}$ & $\begin{array}{l}377 \mathrm{uA} \mathrm{h} \mathrm{cm}^{-2} \\
\text { at } 0.5 \mathrm{~mA} \mathrm{~cm}{ }^{-2}\end{array}$ & 100 & {$[31]$} \\
\hline 8-Sn@C & $\begin{array}{l}349 \mathrm{~mA} \mathrm{~h} \mathrm{~g}^{-1} \\
\text { at } 4 \mathrm{~A} \mathrm{~g}^{-1}\end{array}$ & $\begin{array}{l}415 \mathrm{~mA} \mathrm{~h} \mathrm{~g}^{-1} \\
\text { at } 1 \mathrm{~A} \mathrm{~g}^{-1}\end{array}$ & 500 & {$[32]$} \\
\hline Porous C/Sn & At $20 \mathrm{~mA} \mathrm{~g}^{-1}$ & $200 \mathrm{~mA} \mathrm{~h} \mathrm{~g}^{-1}$ & 15 & {$[42]$} \\
\hline C@Sn@N-doped carbon & $\begin{array}{l}124.1 \mathrm{mAh} \mathrm{g}^{-1} \\
\text { at } 2 \mathrm{~A} \mathrm{~g}^{-1}\end{array}$ & $\begin{array}{l}\quad 398.4 \mathrm{~mA} \mathrm{~h} \mathrm{~g}^{-1} \\
\text { at } 100 \mathrm{~mA} \mathrm{~g}^{-1}\end{array}$ & 150 & this study \\
\hline
\end{tabular}




\section{AUTHOR INFORMATION}

\section{Corresponding Author}

*E-mail: jiazhao@uow.edu.au; Fax: +61 24221 5731; Tel: +61 242981478

\section{Notes}

The authors declare no conflicting financial interests.

\section{ACKNOWLEDGMENTS}

This research work was implemented with financial support from an Australian Research Council (ARC) Discovery Project (DP140100401). This research used instruments funded by the Australian Research Council (ARC) - Linkage, Infrastructure, Equipment and Facilities (LIEF) grant JEOL JEM-2011: LE0237478, along with the facilities situated in the UOW Electron Microscopy Centre. The authors would like to express our gratitude to Dr. Dongqi Shi for XPS measurements and to Dr. Tania Silver for editing the manuscript.

\section{REFERENCES}

1. Nishi, Y., Lithium Ion Secondary Batteries; Past 10 Years and the Future. J. Power Sources 2001, 100 (1), 101-106.

2. $\quad$ Yang, Z.; Zhang, J.; Kintner-Meyer, M. C.; Lu, X.; Choi, D.; Lemmon, J. P.; Liu, J., Electrochemical Energy Storage for Green Grid. Chem. Rev. 2011, 111 (5), 3577-3613.

3. Chan, C. K.; Peng, H.; Liu, G.; Mcllwrath, K.; Zhang, X. F.; Huggins, R. A.; Cui, Y., High-Performance Lithium Battery Anodes Using Silicon Nanowires. Nat. Nanotechnol. 2008, 3 (1), 31-35. 
4. Kovalenko, I.; Zdyrko, B.; Magasinski, A.; Hertzberg, B.; Milicev, Z.; Burtovyy, R.; Luzinov, I.; Yushin, G., A Major Constituent of Brown Algae for Use in High-Capacity Li-Ion Batteries. Science 2011, 334 (6052), 75-79.

5. Armand, M.; Tarascon, J., Key Challenges in Future Li-Battery Research. Nature 2008, 451,652 .

6. Palacin, M. R., Recent Advances in Rechargeable Battery Materials: A Chemist's Perspective. Chem. Soc. Rev. 2009, 38 (9), 2565-2575.

7. $\quad$ Palomares, V.; Serras, P.; Villaluenga, I.; Hueso, K. B.; Carretero-González, J.; Rojo, T., Na-Ion Batteries, Recent Advances and Present Challenges to Become Low Cost Energy Storage Systems. Energy Environ. Sci. 2012, 5 (3), 5884-5901.

8. Wu, L.; Pei, F.; Mao, R.; Wu, F.; Wu, Y.; Qian, J.; Cao, Y.; Ai, X.; Yang, H., Sic-Sb-C Nanocomposites as High-Capacity and Cycling-Stable Anode for Sodium-Ion Batteries. Electrochim. Acta 2013, 87, 41-45.

9. $\quad$ Park, J.; Park, J.-W.; Han, J.-H.; Lee, S.-W.; Lee, K.-Y.; Ryu, H.-S.; Kim, K.-W.; Wang, G.; Ahn, J.-H.; Ahn, H.-J., Charge-Discharge Properties of Tin Dioxide for Sodium-Ion Battery. Mater. Res. Bull. 2014, 58, 186-189.

10. Wang, Y.; Su, D.; Wang, C.; Wang, G., Sno 2@ Mwcnt Nanocomposite as a High Capacity Anode Material for Sodium-Ion Batteries. Electrochem. Commun. 2013, 29, 8-11.

11. Qian, J.; Chen, Y.; Wu, L.; Cao, Y.; Ai, X.; Yang, H., High Capacity Na-Storage and Superior Cyclability of Nanocomposite Sb/C Anode for Na-Ion Batteries. Chem. Commun. 2012, 48 (56), 7070-7072.

12. Bommier, C.; Luo, W.; Gao, W.-Y.; Greaney, A.; Ma, S.; Ji, X., Predicting Capacity of Hard Carbon Anodes in Sodium-Ion Batteries Using Porosity Measurements. Carbon 2014, 76, 165-174.

13. Dahbi, M.; Nakano, T.; Yabuuchi, N.; Ishikawa, T.; Kubota, K.; Fukunishi, M.; Shibahara, S.; Son, J.-Y.; Cui, Y.-T.; Oji, H., Sodium Carboxymethyl Cellulose as a Potential Binder for Hard-Carbon Negative Electrodes in Sodium-Ion Batteries. Electrochem. Commun. 2014, 44, 66-69.

14. Sun, Q.; Ren, Q.-Q.; Li, H.; Fu, Z.-W., High Capacity Sb 2 O 4 Thin Film Electrodes for Rechargeable Sodium Battery. Electrochem. Commun. 2011, 13 (12), 1462-1464.

15. Qin, W.; Chen, T.; Pan, L.; Niu, L.; Hu, B.; Li, D.; Li, J.; Sun, Z., Mos 2-Reduced Graphene Oxide Composites Via Microwave Assisted Synthesis for Sodium Ion Battery Anode with Improved Capacity and Cycling Performance. Electrochim. Acta 2015, 153, 55-61.

16. Liu, X.; Chen, T.; Chu, H.; Niu, L.; Sun, Z.; Pan, L.; Sun, C. Q., Fe 2 O 3-Reduced Graphene Oxide Composites Synthesized Via Microwave-Assisted Method for Sodium Ion Batteries. Electrochim. Acta 2015, 166, 12-16. 
17. Xiong, H.; Slater, M. D.; Balasubramanian, M.; Johnson, C. S.; Rajh, T., Amorphous Tio2 Nanotube Anode for Rechargeable Sodium Ion Batteries. J. Phys. Chem. Lett. 2011, 2 (20), 2560-2565.

18. Zhou, X.; Dai, Z.; Bao, J.; Guo, Y.-G., Wet Milled Synthesis of an Sb/Mwent Nanocomposite for Improved Sodium Storage. J. Mater. Chem. A 2013, I (44), 13727-13731.

19. Zhang, J.; Yin, Y.-X.; Guo, Y.-G., High-Capacity Te Anode Confined in Microporous Carbon for Long-Life Na-Ion Batteries. ACS Appl. Mater. Interfaces 2015, 7 (50), 27838-27844.

20. Li, W.; Chou, S. L.; Wang, J. Z.; Kim, J. H.; Liu, H. K.; Dou, S. X., Sn4+ Xp3@ Amorphous Sn - P Composites as Anodes for Sodium - Ion Batteries with Low Cost, High Capacity, Long Life, and Superior Rate Capability. Adv. Mater. 2014, 26 (24), 4037-4042.

22. Kim, Y.; Park, Y.; Choi, A.; Choi, N. S.; Kim, J.; Lee, J.; Ryu, J. H.; Oh, S. M.; Lee, K. T., An Amorphous Red Phosphorus/Carbon Composite as a Promising Anode Material for Sodium Ion Batteries. Adv. Mater. 2013, 25 (22), 3045-3049.

22. Sun, J.; Lee, H.-W.; Pasta, M.; Yuan, H.; Zheng, G.; Sun, Y.; Li, Y.; Cui, Y., A Phosphorene-Graphene Hybrid Material as a High-Capacity Anode for Sodium-Ion Batteries. Nat. Nanotechnol. 2015, 10 (11), 980-985.

23. Li, W.-J.; Chou, S.-L.; Wang, J.-Z.; Liu, H.-K.; Dou, S.-X., Simply Mixed Commercial Red Phosphorus and Carbon Nanotube Composite with Exceptionally Reversible Sodium-Ion Storage. Nano Lett. 2013, 13 (11), 5480-5484.

24. Li, Z.; Ding, J.; Mitlin, D., Tin and Tin Compounds for Sodium Ion Battery Anodes: Phase Transformations and Performance. Acc. Chem. Res. 2015, 48 (6), 1657-1665.

25. Wang, J. W.; Liu, X. H.; Mao, S. X.; Huang, J. Y., Microstructural Evolution of Tin Nanoparticles During in Situ Sodium Insertion and Extraction. Nano Lett. 2012, 12 (11), 58975902.

26. Komaba, S.; Matsuura, Y.; Ishikawa, T.; Yabuuchi, N.; Murata, W.; Kuze, S., Redox Reaction of Sn-Polyacrylate Electrodes in Aprotic Na Cell. Electrochem. Commun. 2012, 21, $65-$ 68.

27. Farbod, B.; Cui, K.; Kalisvaart, W. P.; Kupsta, M.; Zahiri, B.; Kohandehghan, A.; Lotfabad, E. M.; Li, Z.; Luber, E. J.; Mitlin, D., Anodes for Sodium Ion Batteries Based on TinGermanium-Antimony Alloys. ACS nano 2014, 8 (5), 4415-4429.

28. Lin, Y.-M.; Abel, P. R.; Gupta, A.; Goodenough, J. B.; Heller, A.; Mullins, C. B., Sn-Cu Nanocomposite Anodes for Rechargeable Sodium-Ion Batteries. ACS Appl. Mater. Interfaces 2013, 5 (17), 8273-8277.

29. Liu, Y.; Xu, Y.; Zhu, Y.; Culver, J. N.; Lundgren, C. A.; Xu, K.; Wang, C., Tin-Coated Viral Nanoforests as Sodium-Ion Battery Anodes. Acs Nano 2013, 7 (4), 3627-3634. 
30. Zhu, H.; Jia, Z.; Chen, Y.; Weadock, N.; Wan, J.; Vaaland, O.; Han, X.; Li, T.; Hu, L., Tin Anode for Sodium-Ion Batteries Using Natural Wood Fiber as a Mechanical Buffer and Electrolyte Reservoir. Nano Lett. 2013, 13 (7), 3093-3100.

31. Xie, X.; Kretschmer, K.; Zhang, J.; Sun, B.; Su, D.; Wang, G., Sn@ Cnt Nanopillars Grown Perpendicularly on Carbon Paper: A Novel Free-Standing Anode for Sodium Ion Batteries. Nano Energy 2015, 13, 208-217.

32. Liu, Y.; Zhang, N.; Jiao, L.; Tao, Z.; Chen, J., Ultrasmall Sn Nanoparticles Embedded in Carbon as High - Performance Anode for Sodium - Ion Batteries. Adv. Funct. Mater. 2015, 25 (2), 214-220.

33. Wang, H. g.; Wu, Z.; Meng, F. 1.; Ma, D. 1.; Huang, X. 1.; Wang, L. m.; Zhang, X. b., Nitrogen - Doped Porous Carbon Nanosheets as Low - Cost, High - Performance Anode Material for Sodium - Ion Batteries. ChemSusChem 2013, 6 (1), 56-60.

34. Fu, L.; Tang, K.; Song, K.; van Aken, P. A.; Yu, Y.; Maier, J., Nitrogen Doped Porous Carbon Fibres as Anode Materials for Sodium Ion Batteries with Excellent Rate Performance. Nanoscale 2014, 6 (3), 1384-1389.

35. Wang, Z.; Qie, L.; Yuan, L.; Zhang, W.; Hu, X.; Huang, Y., Functionalized N-Doped Interconnected Carbon Nanofibers as an Anode Material for Sodium-Ion Storage with Excellent Performance. Carbon 2013, 55, 328-334.

36. Ruan, B.; Wang, J.; Shi, D.; Xu, Y.; Chou, S.; Liu, H.; Wang, J., A Phosphorus/N-Doped Carbon Nanofiber Composite as an Anode Material for Sodium-Ion Batteries. J. Mater. Chem. A 2015, 3 (37), 19011-19017.

37. Yang, X.; Zhu, Z.; Dai, T.; Lu, Y., Facile Fabrication of Functional Polypyrrole Nanotubes Via a Reactive Self - Degraded Template. Macromol. Rapid Commun. 2005, 26 (21), 1736-1740.

38. Park, M.-S.; Kang, Y.-M.; Kim, J.-H.; Wang, G.-X.; Dou, S.-X.; Liu, H.-K., Effects of Low-Temperature Carbon Encapsulation on the Electrochemical Performance of Sno 2 Nanopowders. Carbon 2008, 46 (1), 35-40.

39. Zhu, Z.; Wang, S.; Du, J.; Jin, Q.; Zhang, T.; Cheng, F.; Chen, J., Ultrasmall Sn Nanoparticles Embedded in Nitrogen-Doped Porous Carbon as High-Performance Anode for Lithium-Ion Batteries. Nano Lett. 2013, 14 (1), 153-157.

40. Jahel, A.; Ghimbeu, C. M.; Darwiche, A.; Vidal, L.; Hajjar-Garreau, S.; Vix-Guterl, C.; Monconduit, L., Exceptionally Highly Performing Na-Ion Battery Anode Using Crystalline $\mathrm{SnO}_{2}$ Nanoparticles Confined in Mesoporous Carbon. J. Mater. Chem. A 2015, 3 (22), 11960-11969.

41. http://chemistry.about.com/od/moleculescompounds/a/Table-Of-Electrical-Resistivity-AndConductivity.htm 
42. Xu, Y.; Zhu, Y.; Liu, Y.; Wang, C., Electrochemical Performance of Porous Carbon/Tin Composite Anodes for Sodium - Ion and Lithium - Ion Batteries. Adv. Energy Mater. 2013, 3 (1), 128-133.

43. Chen, W.; Deng, D., Sodium-Cutting: A New Top-Down Approach to Cut Open Nanostructures on Nonplanar Surfaces on a Large Scale. Chem. Commun. 2014, 50 (87), 13327 13330 .

44. Liu, Y.; Xu, Y.; Zhu, Y.; Culver, J. N.; Lundgren, C. A.; Xu, K.; Wang, C., Tin-Coated Viral Nanoforests as Sodium-Ion Battery Anodes. ACS Nano 2013, 7 (4), 3627-3634.

45. Su, F.; Poh, C. K.; Chen, J. S.; Xu, G.; Wang, D.; Li, Q.; Lin, J.; Lou, X. W., NitrogenContaining Microporous Carbon Nanospheres with Improved Capacitive Properties. Energy Environ. Sci. 2011, 4 (3), 717-724. 


\section{TOC}

\section{C@Sn}

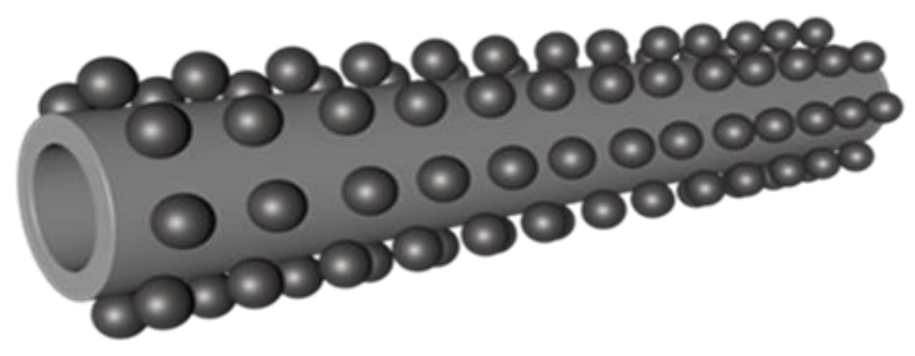

